\title{
Thermodynamic Equilibrium Conditions for Simulated Landfill Gas Hydrate Formation in Aqueous Solutions of Additives
}

\author{
Zhi-Ming Xia, ${ }^{\dagger,}$ Zhao-Yang Chen, ${ }^{\dagger, \ddagger}$ Xiao-Sen Li, ${ }^{, \dagger, \ddagger}$ Yu Zhang, ${ }^{\dagger,+}$ Ke-Feng Yan, ${ }^{\dagger,}$ Qiu-Nan Lv, ${ }^{\dagger \neq}$ \\ Chun-Gang $\mathrm{Xu},{ }^{\dagger, \ddagger}$ and Jing Cai ${ }^{\dagger, \ddagger}$
}

${ }^{\dagger}$ Key Laboratory of Renewable Energy and Gas Hydrate, Guangzhou Institute of Energy Conversion, Chinese Academy of Sciences,
Guangzhou 510640, People’s Republic of China
${ }^{\ddagger}$ Guangzhou Center for Gas Hydrate Research, Chinese Academy of Sciences, Guangzhou 510640, People’s Republic of China

ABSTRACT: This work presents the thermodynamic study of separating $\mathrm{CH}_{4}$ and $\mathrm{CO}_{2}$ from the simulated landfill gas (LFG) $\left[\mathrm{CO}_{2}(0.45)+\mathrm{CH}_{4}(0.55)\right]$ based on hydrate crystallization in the presence of tetra- $n$-butyl ammonium bromide (TBAB), tetrahydrofuran (THF), dimethyl sulfoxide (DMSO), and their mixtures. The mole fractions of TBAB, THF, and DMSO aqueous solutions were fixed at $0.0234,0.0556$, and 0.0165 , respectively. The equilibrium hydrate formation conditions were measured by $T$-cycle method in the temperature range of (274.15 to 294.95$) \mathrm{K}$ and the pressure ranges up to 6.72 $\mathrm{MPa}$. The gas phase in the crystallizer at the equilibrium points was also sampled

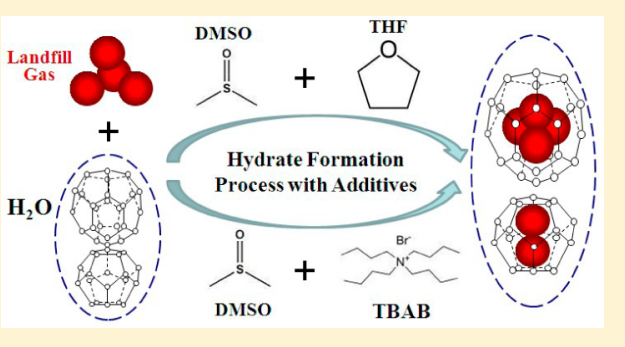
and analyzed. For the additives with the fixed concentrations studied in this work, it was found that both TBAB and THF can remarkably reduce the equilibrium hydrate formation pressure of LFG mixture gas, but the effect of THF is better than that of $\mathrm{TBAB}$ in the high temperature region, while DMSO have no obvious pressure drop effect on the equilibrium hydrate formation conditions but can promote the solubility of $\mathrm{CO}_{2}$ in the solution. However, the mixture additives of TBAB $+\mathrm{DMSO}$ and THF + DMSO can not only remarkably promote the solubility of $\mathrm{CO}_{2}$ but also remarkably reduce the equilibrium hydrate formation pressure of $\mathrm{CO}_{2}+\mathrm{CH}_{4}+\mathrm{H}_{2} \mathrm{O}$ hydrate. Moreover, the pressure drop effect of THF + DMSO is better than that of TBAB + DMSO on the $\mathrm{CO}_{2}+\mathrm{CH}_{4}+\mathrm{H}_{2} \mathrm{O}$ equilibrium hydrate formation in the high temperature region.

\section{INTRODUCTION}

Landfill gas (LFG) is currently generated through biological degradation of the biodegradable organic faction of waste in landfill sites and mainly consists of methane $\left(\mathrm{CH}_{4}\right)(0.50$ to 0.60 mole fraction) and carbon dioxide $\left(\mathrm{CO}_{2}\right)(0.40$ to 0.50 mole fraction). ${ }^{1}$ It is acknowledged that both $\mathrm{CH}_{4}$ and $\mathrm{CO}_{2}$ are the major greenhouse gases (GHG), and reducing $\mathrm{CH}_{4}$ and $\mathrm{CO}_{2}$ emissions from landfills will have an important role in stabilizing GHG concentration in the atmosphere and preventing serious anthropogenic climate change. ${ }^{2,3}$ On the other hand, LFG can be used as a kind of renewable bioenergy resource due to its high calorific value. According to Wang et al., the calorific values vary between $(15$ and 20$) \mathrm{MJ} \cdot \mathrm{m}^{-3}$ when the $\mathrm{CH}_{4}$ components in the LFG range from $45 \%$ to $60 \%$. However, the removal of $\mathrm{CO}_{2}$ from the landfill gas is very important in this case since it is the prerequisite process to enhance its calorific values and reduce the greenhouse effect. Numerous ways can achieve this goal, ${ }^{5}$ such as absorption, ${ }^{6,7}$ adsorption, ${ }^{7}$ cryogenic fractionation, ${ }^{8}$ and membrane separation. ${ }^{9}$ These processes prove successful for the selective removal of $\mathrm{CO}_{2}$, but their major drawback is the large energy cost.

Removing $\mathrm{CO}_{2}$ selectively from a gas mixture by clathrate hydrate crystallization has been proposed by several groups. ${ }^{10-21}$ Clathrate hydrates are nonstoichiometric crystalline inclusion compounds consisting of a network of hydrogenbonded water molecules, ${ }^{22}$ in which different types of low molecular weight compounds can be enclathrated when the appropriate conditions of moderately low temperature (a few degrees above $273.15 \mathrm{~K}$ ) and high pressure (in the range of a few $\mathrm{MPa}$ ) are met. When the mixture gas formed hydrate with water aqueous solution, the component possessing a milder condition of hydrate formation will enrich in the hydrate phase. ${ }^{23}$ For this reason, gas hydrate crystallization can be used as a potential separation process for $\mathrm{CO}_{2}$ capture. It is wellknown that $\mathrm{CO}_{2}$ can form the hydrates under the milder conditions than $\mathrm{CH}_{4}{ }^{22}$ Hence, the high selectivity can be expected for separating $\mathrm{CO}_{2}$ from its mixtures accompanied with $\mathrm{CH}_{4}$. On the other hand, the hydrate formation processes will consume considerable energy for pressuring the feed gas and cooling the solution due to the rigorous operating conditions. ${ }^{23}$ Therefore, thermodynamic additives such as tetrahydrofuran (THF), tetrabutylammonium bromide $(\mathrm{TBAB})$, and cyclopentane $(\mathrm{CP})$ are encouraged to reduce the financial impact of such a phenomenon. Kang and Lee reported the equilibrium hydrate formation conditions of the mixture gas of $\mathrm{CO}_{2}(0.17)+\mathrm{N}_{2}(0.83)$ in the presence of mole fraction of $0.01 \mathrm{THF}^{24}$ and found that THF can remarkably reduce the equilibrium hydrate formation pressure. Three independent groups reported the thermodynamic studies of

Received: August 25, 2012

Accepted: October 15, 2012

Published: October 26, 2012 
TBAB semiclathrates formed from $\mathrm{CO}_{2}$ mixture gases for potential applications for $\mathrm{CO}_{2}$ capture from flue gas and fuel gas. ${ }^{12,19-21}$ Our previous work also studied the TBAB hydrate process for removing $\mathrm{CO}_{2}$ from fuel gas in terms of thermodynamic, kinetic, and separation efficiency. ${ }^{15,16,18}$

While in the case of recovering $\mathrm{CO}_{2}$ from the LFG by hydrate process, it should be noted that only a limited amount of thermodynamic data currently available reported by Acosta et al. in the open literature. ${ }^{17}$ They reported the thermodynamic data of TBAB semiclathrates formed from simulated LFG when the experimental temperature, pressure, mass fraction of $\mathrm{TBAB}$, and mole fraction of $\mathrm{CO}_{2}$ in the mixture gas ranged from (286 to 293$) \mathrm{K}$, from (3 to 6.5) $\mathrm{MPa},(0.05$, 0.10 and 0.20$)$, and (0.4 and 0.6), respectively. However, to our best knowledge, there is no research on the thermodynamic study of the hydrate process from simulated LFG $\left(\mathrm{CO}_{2}(0.45)\right.$ $+\mathrm{CH}_{4}(0.55)$ ) with TBAB, THF, dimethyl sulfoxide (DMSO), and the mixture of them. DMSO has been reported as an important industrial gas solvent due to its properties in water solutions. ${ }^{25,26}$ With the expectation that DMSO can promote the solubility of $\mathrm{CO}_{2}$ in water and promote the $\mathrm{CO}_{2}$ hydrate formation, and $\mathrm{TBAB}$ and $\mathrm{THF}$ can reduce the equilibrium hydrate formation pressure of landfill gas, it is significant to study the thermodynamic properties of the hydrate formation from landfill gas with the mixture of the traditional hydrate promoters and a gas solubility promoter.

In this work, the equilibrium hydrate formation conditions of $\mathrm{CO}_{2}(0.45)+\mathrm{CH}_{4}(0.55)$ mixture with DMSO, TBAB, THF, $\mathrm{THF}+\mathrm{DMSO}$, and $\mathrm{TBAB}+\mathrm{DMSO}$ aqueous solutions and with pure water were measured. The mole fraction of TBAB, THF, and DMSO aqueous solutions were fixed at 0.0234, 0.0556 , and 0.0165 , respectively. The gas phase in the crystallizer was also sampled and analyzed at the equilibrium points. The $\mathrm{CO}_{2}(0.45)+\mathrm{CH}_{4}(0.55)$ was simulated as the LFG due to that LFG is a mixture of $\mathrm{CO}_{2}$ ( 0.50 to 0.60 mole fraction) and $\mathrm{CH}_{4}$ ( 0.40 to 0.50 mole fraction) along with trace amounts of nitrogen $\left(\mathrm{N}_{2}\right)$ in practice. ${ }^{1,27}$ However, relative to $\mathrm{CO}_{2}$, the equilibrium hydrate formation pressure of $\mathrm{N}_{2}$ is close to that of $\mathrm{CH}_{4}$. Thus, for means of simplification, the ternary systems containing $\mathrm{N}_{2}$ can be simulated as a binary system of $\mathrm{CO}_{2}$ and $\mathrm{CH}_{4}$ in this study.

\section{EXPERIMENTAL SECTION}

Materials. The chemicals including their suppliers and purities used in this work are listed in Table 1. The chemicals were used without any further purification.

Apparatus. Briefly, the main part of the experimental apparatus is a cylindrical high-pressure stainless steel crystallizer (CR); its inner volume and the maximum working pressure are $336 \mathrm{~mL}$ and $25 \mathrm{MPa}$, respectively. The crystallizer has two circular viewing windows on the front and the back. A magnetic stirrer $\left(450 \mathrm{r} \cdot \mathrm{min}^{-1}\right)$ that is driven by an electric motor (Shanghai Meiyinpu Instrument, Ltd., China) is installed in the crystallizer to agitate the fluids and hydrate crystals. Two Pt1000 thermoprobes (JM6081) with a $\pm 0.1 \mathrm{~K}$ accuracy are inserted into the crystallizer to measure the temperatures in the gas phase and in the hydrate slurry phase, respectively. All pressures are measured by Setra smart pressure transducers (model 552, Boxborough, MA, USA) with the pressures ranging up to $25 \mathrm{MPa}$ and the accuracy of $\pm 0.02 \mathrm{MPa}$. All of the temperature and pressure data from the acquisition system are saved at preset sampling intervals on a personal computer (PC). The temperature of the crystallizer is controlled by a
Table 1. Experimental Materials Used in This Work ${ }^{a}$

\begin{tabular}{|c|c|c|}
\hline material & $\begin{array}{l}\text { mole } \\
\text { fraction } \\
\text { purity }\end{array}$ & supplier \\
\hline methane & 0.99 & $\begin{array}{l}\text { South China Special Gases Institute } \\
\text { Co., Ltd. China }\end{array}$ \\
\hline carbon dioxide & 0.99 & $\begin{array}{l}\text { South China Special Gases Institute } \\
\text { Co., Ltd. China }\end{array}$ \\
\hline $\begin{array}{l}\text { tetra- } n \text {-butyl } \\
\text { ammonium bromide }\end{array}$ & 0.9999 & $\begin{array}{l}\text { Shanghai Sinopharm Chemical } \\
\text { Reagent Co., Ltd., China }\end{array}$ \\
\hline tetrahydrofuran & 0.9999 & $\begin{array}{l}\text { Shanghai Sinopharm Chemical } \\
\text { Reagent Co., Ltd., China }\end{array}$ \\
\hline dimethyl sulfoxide & 0.9999 & $\begin{array}{l}\text { Shanghai Sinopharm Chemical } \\
\text { Reagent Co., Ltd., China }\end{array}$ \\
\hline
\end{tabular}

${ }^{a}$ Aqueous solutions were prepared following the gravimetric method, using an accurate analytical balance. Consequently, uncertainties on the basis of mole fraction are estimated to be $<0.01$.

thermostatic water bath. The gas samples in the crystallizer at the phase equilibrium points are analyzed by a Wufeng GC522 gas chromatography (GC) (Shanghai Wufeng Scientific Instrument Co., Ltd., China.) immediately. A schematic diagram of the experimental apparatus is shown in Figure 1.



Figure 1. Schematic diagram of the experimental apparatus. FGC, feed gas cylinder; PG, pressure regulator; PC, personal computer; V1 to V4, valve; PT, pressure transducer; GC, gas chromatographer; FWV, fourway valve; SM, stirring motor; TC, temperature controller; $\mathrm{TP}$, thermoprobe; CR, crystallizer; WB, water bath; MS, magnetic stirrer.

Experimental Procedure. The experimental procedure employed in this work was T-cycle method, which almost identical to that used by Ohgaki et al., Hashimoto et al., and $\mathrm{Li}$ et al., ${ }^{15,28,29}$ except for an additional step for sampling and analyzing the gas phase in the crystallizer at the equilibrium conditions. After cleaning with deionized water and drying, the high-pressure hydrate crystallizer was initially charged with approximately $180 \mathrm{~mL}$ of additive aqueous solution which was prepared at the desired concentration. Subsequently, the hydrate crystallizer filled with the additive aqueous solution was evacuated with a vacuum pump and purged with the $\mathrm{CO}_{2}+$ $\mathrm{CH}_{4}$ mixture gas four to five times to ensure the absence of any remnant gas. The $\mathrm{CO}_{2}+\mathrm{CH}_{4}$ mixture gas was supplied from the feed gas cylinder through a pressure regulate valve into the hydrate crystallizer. Once the hydrate crystallizer was pressurized up to the desired pressure, the system was cooled and agitated to form the mixed gas hydrate. The hydrate 
formation phenomenon can be integrative determined by observing through the circular viewing windows and the pressure depression caused by the hydrate formation. Subsequently, the system was heated quite gradually with each temperature step of $0.1 \mathrm{~K}$ until there was an infinitesimal amount of gas hydrate left. The interval time was taken at least for one day for determining the equilibrium state at each temperature step. Until no particle of hydrates appeared during the gradual heating, we determined this point as the equilibrium point. ${ }^{15,29,30}$ Once the equilibrium point was determined, the sampling line was flushed with inert argon, and the gas phase in the hydrate crystallizer was subsequently sampled and then analyzed with GC. ${ }^{17}$

\section{RESULTS AND DISCUSSION}

Equilibrium Conditions for $\mathrm{CO}_{2}+\mathrm{CH}_{4}+\mathrm{H}_{2} \mathrm{O}$ Mixture Hydrate. Prior to the experiment for $\mathrm{CO}_{2}+\mathrm{CH}_{4}+\mathrm{H}_{2} \mathrm{O}+$ TBAB hydrate system, four equilibrium hydrate formation points of the $\mathrm{CO}_{2}(0.45)+\mathrm{CH}_{4}(0.55)$ mixture gas were measured in the temperature range of (274.15 to 278.75$) \mathrm{K}$ and compared with the equilibrium hydrate formation data of the $\mathrm{CO}_{2}(0.50)+\mathrm{CH}_{4}(0.50)$ gas mixture given by Gaudette ${ }^{30}$ and Servio et al. ${ }^{31}$ As shown in Figure 2, at any certain temperature,

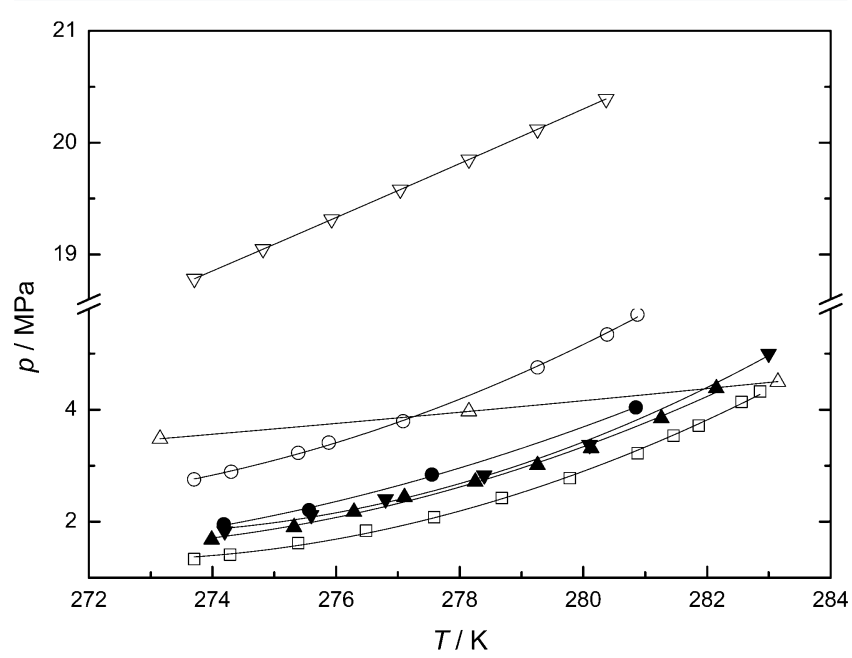

Figure 2. Equilibrium hydrate formation pressure for $\mathrm{CH}_{4}(1)+\mathrm{CO}_{2}$ (2) mixture hydrate: $\mathrm{O}, y_{1}=1.00, y_{2}^{\prime}=0.00$, Deaton and Frost; ${ }^{32} \boldsymbol{\bullet}, y_{1}$ $=0.55, y_{2}=0.45$, this work; $\mathbf{\Delta}, y_{1}=0.50, y_{2}=0.50$, Gaudette ${ }^{30} \boldsymbol{\nabla}, y_{1}$ $=0.50, y_{2}=0.50$, Servio et al.; ${ }^{31} \square, y_{1}=0.00, y_{2}=1.00$, Deaton and Frost; ${ }^{32} \triangle$, vapor pressure of pure $\mathrm{CO}_{2}$, Matvienko and YarymAgaev; ${ }^{35} \nabla$, vapor pressure of $\mathrm{CH}_{4}$, Lu et al. ${ }^{36}$.

the equilibrium pressure of the $\mathrm{CO}_{2}+\mathrm{CH}_{4}$ mixture hydrate is between that of the unitary $\mathrm{CO}_{2}$ hydrate and $\mathrm{CH}_{4}$ hydrate. ${ }^{32}$ Furthermore, the equilibrium hydrate formation pressure of $\mathrm{CO}_{2}(0.45)+\mathrm{CH}_{4}(0.55)$ mixture gas is slightly higher than that of $\mathrm{CO}_{2}(0.50)+\mathrm{CH}_{4}(0.50)$ gas due to the composition difference. It also demonstrates that the equilibrium hydrate formation pressure of the $\mathrm{CO}_{2}+\mathrm{CH}_{4}+\mathrm{H}_{2} \mathrm{O}$ hydrate decreases with the increase of the composition of $\mathrm{CO}_{2}$ in the mixture gas.

Equilibrium Conditions of Pure Additive Aqueous Solutions. Before studying the equilibrium hydrate formation conditions of the simulated LFG gas in the aqueous solution with additives, the equilibrium formation conditions of pure $\mathrm{TBAB}, \mathrm{THF}, \mathrm{TBAB}+\mathrm{DMSO}$, and $\mathrm{THF}+\mathrm{DMSO}$ aqueous solutions hydrate were measured and are listed in Table 1 . The mole fractions of TBAB, THF, and DMSO aqueous solutions were fixed at $0.0234,0.0556$, and 0.0165 , respectively. Figure 3 shows the equilibrium hydrate formation condition of pure

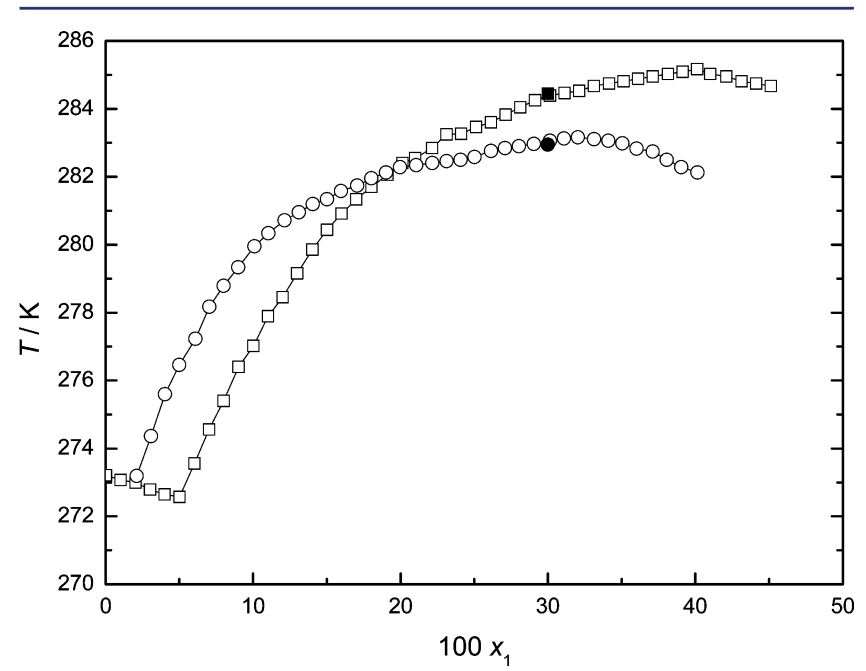

Figure 3. Hydrate phase equilibrium conditions for $\mathrm{TBAB}(3)+$ DMSO (5) $+\mathrm{H}_{2} \mathrm{O}(6)$ aqueous solutions. $\square$, Type-A TBAB hydrate, Oyama et al.; ${ }^{33}$ O, Type-B TBAB hydrate, Oyama et al.; ${ }^{33} \mathbf{\square}, x_{3}=$ $0.0234, x_{5}=0.0$, this work; $\boldsymbol{\Theta}, x_{3}=0.0234, x_{5}=0.0156$, this work.

$\mathrm{TBAB}$ and $\mathrm{TBAB}+\mathrm{DMSO}$ mixture aqueous solutions in this work and the experimental values of pure $\mathrm{TBAB}$ aqueous solution given by Oyama et al. ${ }^{33}$ It can be seen from Figure 3 that the hydrate forms from 0.0234 mole fraction of TBAB aqueous solution are thermodynamically stable at the Type- $A$ TBAB hydrate curve, and our experimental data of pure TBAB hydrate are in excellent agreement with the literature data. ${ }^{33}$ Furthermore, it is interesting to find that the hydrate decomposition temperature of 0.0234 mole fraction TBAB aqueous solution without DMSO is $284.45 \mathrm{~K}$, while that of 0.0234 mole fraction $\mathrm{TBAB}$ with 0.0165 mole fraction DMSO is $282.95 \mathrm{~K}$, which is close to the decomposition temperature of the Type-A TBAB hydrate curve and is obviously lower than that of the Type-A TBAB hydrate curve. It indicates that the addition of DMSO may be lower the decomposition temperature of TBAB pure hydrate; in other words, the addition of DMSO reduces the stability of TBAB hydrate from Type A to Type B. Figure 4 shows the equilibrium formation condition of pure THF and THF + DMSO mixture aqueous solutions in this work and the experimental values of pure THF aqueous solution given by Delahaye et $\mathrm{al}^{34}$ The similar phenomenon also can be seen in the case of THF with DMSO. As shown in Figure 4, the hydrate decomposition temperature of THF + DMSO $+\mathrm{H}_{2} \mathrm{O}$ mixture hydrate is $276.15 \mathrm{~K}$, which is obviously lower than that of the 0.0556 mole fraction THF aqueous solution without DMSO.

Equilibrium Conditions for $\mathrm{CO}_{2}+\mathrm{CH}_{4}+\mathrm{H}_{2} \mathrm{O}$ Mixture Hydrate Formation with Different Additives. The measurements of equilibrium hydrate formation conditions for the $\mathrm{CO}_{2}(0.45)+\mathrm{CH}_{4}(0.55)$ mixture gas with $\mathrm{TBAB}$, THF, DMSO, TBAB + DMSO, and THF + DMSO aqueous solutions in the pressure range of (0.44 to 4.3$) \mathrm{MPa}$ and temperatures in the range of (274.25 to 294.95$) \mathrm{K}$ were carried out. For all of the experiments, the mole concentrations of TBAB, THF, and DMSO aqueous solutions were fixed at $0.0234,0.0556$, and 0.0165 , respectively. The equilibrium temperatures, pressures, and compositions were summarized in Table 2 and plotted in Figures 5 and 6. As shown in Figure 5, 


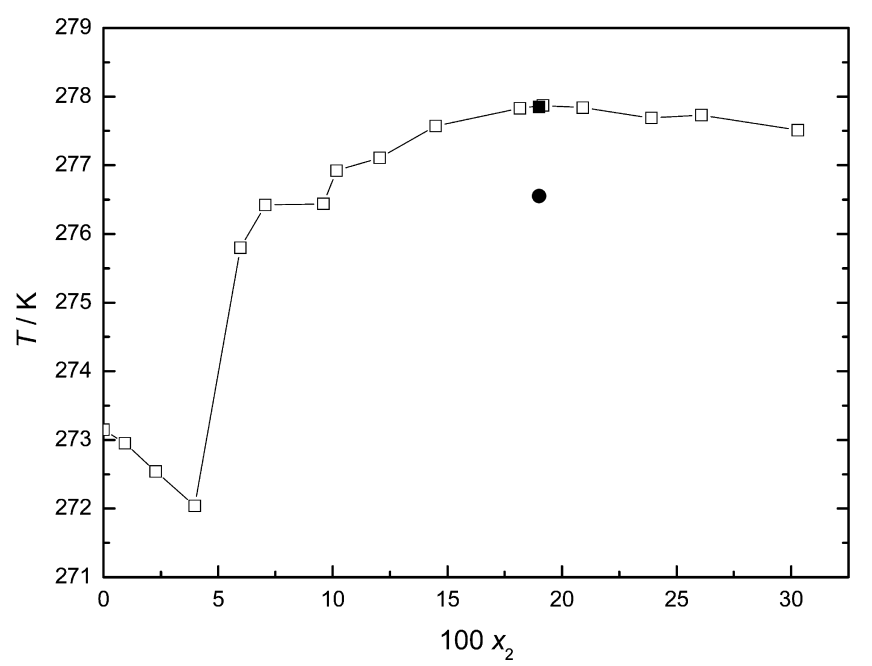

Figure 4. Hydrate phase equilibrium conditions for THF (4) + DMSO (5) $+\mathrm{H}_{2} \mathrm{O}(6)$ aqueous solutions. $\square, x_{4}=0.0$ to $0.3, x_{5}=0.0$, Delahaye et al.; ${ }^{34} \mathbf{\square}, x_{4}=0.0556, x_{5}=0.0$, this work; $\bullet, x_{4}=0.0556, x_{5}=0.0156$, this work.

the equilibrium hydrate formation pressure of the $\mathrm{CO}_{2}+\mathrm{CH}_{4}$ $+\mathrm{H}_{2} \mathrm{O}+$ DMSO mixture hydrate is almost close to that of the $\mathrm{CO}_{2}+\mathrm{CH}_{4}+\mathrm{H}_{2} \mathrm{O}$ mixture hydrate, while the equilibrium hydrate formation pressure of the $\mathrm{CO}_{2}+\mathrm{CH}_{4}+\mathrm{H}_{2} \mathrm{O}+\mathrm{TBAB}$ and $\mathrm{CO}_{2}+\mathrm{CH}_{4}+\mathrm{H}_{2} \mathrm{O}+\mathrm{TBAB}+\mathrm{DMSO}$ mixture hydrate is remarkably lower than that of the $\mathrm{CO}_{2}+\mathrm{CH}_{4}+\mathrm{H}_{2} \mathrm{O}$ mixture hydrate. For example, for the certain $(0.45)+\mathrm{CH}_{4}$ (0.55) gas mixture, the equilibrium hydrate formation pressure of the $\mathrm{CO}_{2}$ $+\mathrm{CH}_{4}+\mathrm{H}_{2} \mathrm{O}+\mathrm{DMSO}$ hydrate is $1.83 \mathrm{MPa}$ at $274.25 \mathrm{~K}$, which is close to that of $\mathrm{CO}_{2}+\mathrm{CH}_{4}+\mathrm{H}_{2} \mathrm{O}$ hydrate $(1.90 \mathrm{MPa}$ at $274.15 \mathrm{~K}$ ); the equilibrium hydrate formation pressure of the $\mathrm{CO}_{2}+\mathrm{CH}_{4}+\mathrm{H}_{2} \mathrm{O}$ mixture without any additives is $6.72 \mathrm{MPa}$ at $285.95 \mathrm{~K}$, while that of the $\mathrm{CO}_{2}+\mathrm{CH}_{4}+\mathrm{H}_{2} \mathrm{O}$ mixture with $\mathrm{TBAB}$ and $\mathrm{DMSO}+\mathrm{TBAB}$ aqueous solutions at the same temperature reduces to $(0.67$ and 1.25$) \mathrm{MPa}$, respectively. It means that there is approximately $90 \%$ reduction of the equilibrium pressure on account of the addition of only 0.0234 mole fraction of $\mathrm{TBAB}$, but the addition of DMSO reduces the pressure drop effect of $\mathrm{TBAB}$ from $90 \%$ to about $81 \%$. It demonstrates that the addition of $\mathrm{TBAB}$ can considerably reduces the pressure required to form the $\mathrm{CO}_{2}+\mathrm{CH}_{4}+\mathrm{H}_{2} \mathrm{O}$ mixture hydrate, but DMSO will slightly lower the lower the pressure effect of TBAB on the $\mathrm{CO}_{2}+\mathrm{CH}_{4}+\mathrm{H}_{2} \mathrm{O}$ hydrate when it is in conjunction with $\mathrm{TBAB}$. Figure 6 shows the equilibrium hydrate formation pressure of the $\mathrm{CO}_{2}+\mathrm{CH}_{4}+$ $\mathrm{H}_{2} \mathrm{O}$ mixture hydrate with THF and THF + DMSO and also compares the results of that with pure water and pure DMSO aqueous solutions. As shown in Figure 6, it is obvious that THF can remarkably reduce the equilibrium hydrate formation pressure of $\mathrm{CO}_{2}+\mathrm{CH}_{4}+\mathrm{H}_{2} \mathrm{O}$ mixture hydrate. For example, the equilibrium hydrate formation pressure of the mixture hydrate with THF is only $0.55 \mathrm{MPa}$ at $285.95 \mathrm{~K}$, which is about $91.8 \%$ lower than that of the mixture hydrate without THF. On the other hand, even though the pure DMSO aqueous solution does not have the pressure drop effect on the $\mathrm{CO}_{2}+$ $\mathrm{CH}_{4}+\mathrm{H}_{2} \mathrm{O}+$ DMSO mixture hydrate formation conditions, and the equilibrium hydrate formation conditions of $\mathrm{CO}_{2}+$ $\mathrm{CH}_{4}+\mathrm{H}_{2} \mathrm{O}+$ DMSO mixture hydrate is almost close to that of the $\mathrm{CO}_{2}+\mathrm{CH}_{4}+\mathrm{H}_{2} \mathrm{O}$ mixture hydrate, the THF + DMSO mixture additive still can remarkably reduce the equilibrium
Table 2. Hydrate-Liquid-Vapor Equilibrium Temperature $T$, Pressure $p$ with Standard Uncertainty $u(p)$, and Equilibrium Vapor-Phase Mole Fraction of $\mathrm{CO}_{2} y_{2}^{\prime}$ for $\mathrm{CH}_{4}$ (1) $+\mathrm{CO}_{2}(2)+$ TBAB (3) + THF (4) + DMSO (5) + $\mathrm{H}_{2} \mathrm{O}$ (6) Mixture Hydrate ${ }^{a}$

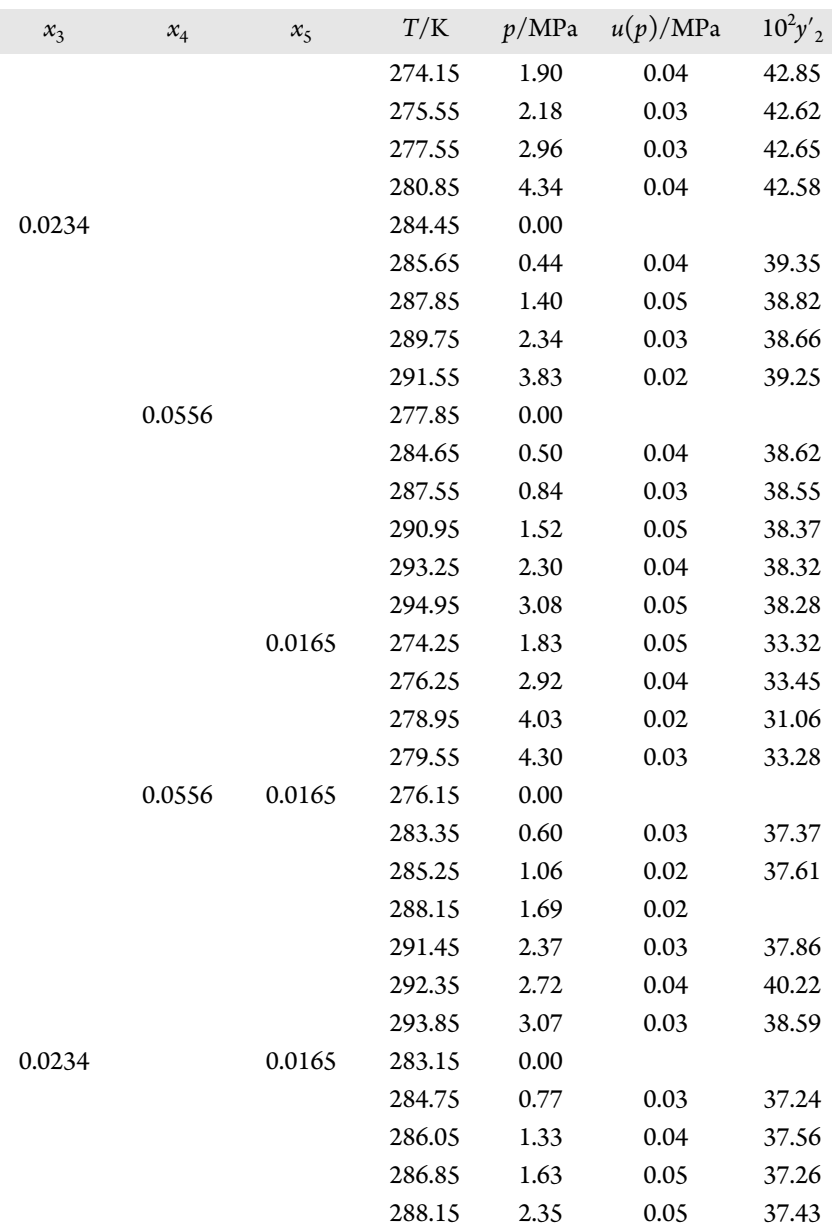

${ }^{a}$ Standard uncertainties $\mathrm{u}$ are $u(T)=0.1 \mathrm{~K}, u(x)=0.0006$, and $u\left(y_{2}^{\prime}\right)$ $=0.0005 ; x_{3}, x_{4}$, and $x_{5}$ denote the component concentration of TBAB, THF, and DMSO in the aqueous solutions, respectively; $y_{1}$ and $y_{2}$ denotes $\mathrm{CH}_{4}$ and $\mathrm{CO}_{2}$ composition in the feed gas, respectively; $y_{2}^{\prime}$ denotes the gas phase composition of $\mathrm{CO}_{2}$ at the equilibrium points.

hydrate formation pressure of the mixture hydrate. For example, the equilibrium hydrate formation pressure of $\mathrm{CO}_{2}$ $+\mathrm{CH}_{4}+\mathrm{H}_{2} \mathrm{O}$ mixture hydrate with THF + DMSO is only 1.16 $\mathrm{MPa}$, which is about $82.73 \%$ lower than that of the mixture hydrate without THF + DMSO.

The pressure drop effects of TBAB, DMSO, TBAB + $\mathrm{DMSO}$, and $\mathrm{TBAB}+\mathrm{DMSO}$ additives on the equilibrium hydrate formation of the $\mathrm{CO}_{2}(0.45)+\mathrm{CH}_{4}(0.55)$ mixture gas were also compared each other and compared with that of $\mathrm{CO}_{2}$ $(0.5)+\mathrm{CH}_{4}(0.5)$ mixture gas with neohexane given by Servio et al. ${ }^{31}$ in Figure 7. As shown in Figure 7, both TBAB and THF have the best pressure drop effect on the $\mathrm{CO}_{2}+\mathrm{CH}_{4}+\mathrm{H}_{2} \mathrm{O}$ mixture hydrate formation among the investigated additives, but the effect of THF is better than that of TBAB in the high temperature region. For example, the equilibrium hydrate formation pressure of $\mathrm{CO}_{2}+\mathrm{CH}_{4}+\mathrm{H}_{2} \mathrm{O}$ hydrate with $\mathrm{TBAB}$ is lower than that with THF at a certain temperature when the temperature below $286.45 \mathrm{~K}$, while the equilibrium hydrate formation pressure of $\mathrm{CO}_{2}+\mathrm{CH}_{4}+\mathrm{H}_{2} \mathrm{O}$ hydrate with $\mathrm{TBAB}$ is 


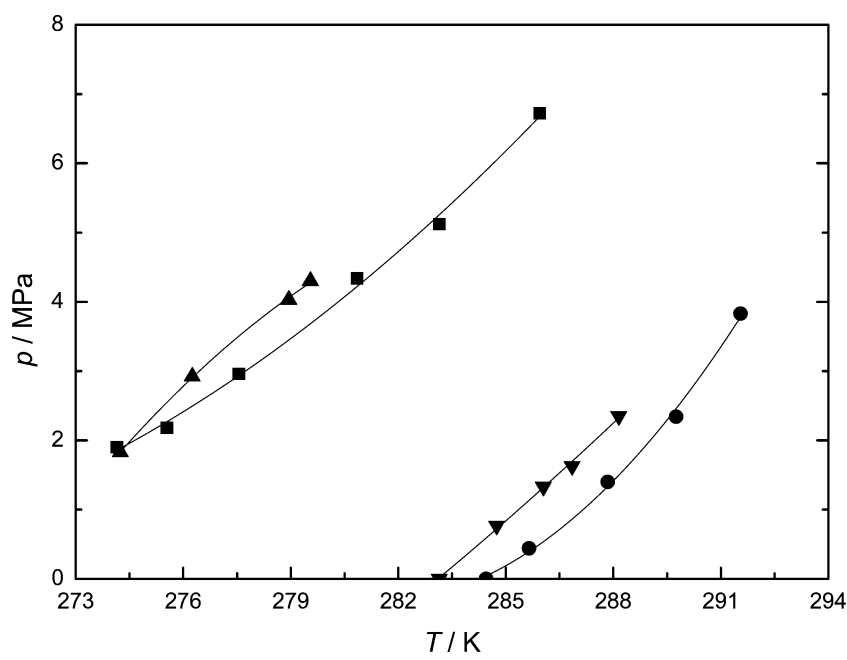

Figure 5. Effects of TBAB (3) + DMSO (5) $+\mathrm{H}_{2} \mathrm{O}$ (6) aqueous solutions on equilibrium hydrate formation pressure of $\mathrm{CH}_{4}(0.55)+$ $\mathrm{CO}_{2}(0.45)$ mixture. $\mathbf{\square}, x_{6}=1.0 ; \boldsymbol{\bullet}, x_{3}=0.0234, x_{5}=0.0 ; \mathbf{\Delta}, x_{3}=0.0$, $x_{5}=0.0156 ; \nabla, x_{3}=0.0234, x_{5}=0.0156$; all of the lines are drawn as fitting curves of the experimental data.

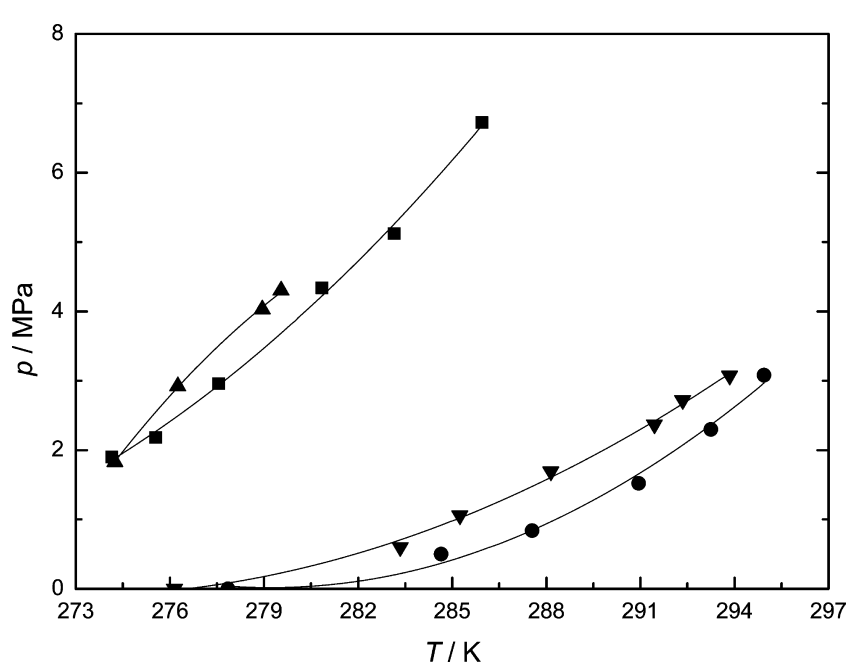

Figure 6. Effects of THF (4) + DMSO (5) $+\mathrm{H}_{2} \mathrm{O}$ (6) aqueous solutions on equilibrium hydrate formation pressure of $\mathrm{CH}_{4}(0.55)+$ $\mathrm{CO}_{2}(0.45)$ mixture. $\mathbf{\square}, x_{6}=1.0 ; \boldsymbol{\bullet}, x_{4}=0.0556, x_{5}=0.0 ; \boldsymbol{\Delta}, x_{4}=0.0$, $x_{5}=0.0156 ; \boldsymbol{\nabla}, x_{4}=0.0556, x_{5}=0.0156$; all of the lines are drawn as fitting curves of the experimental data.

higher than that with THF at a certain temperature when the temperature above $286.45 \mathrm{~K}$. Moreover, the pressure drop effect of TBAB + DMSO is better than that of THF + DMSO on the $\mathrm{CO}_{2}+\mathrm{CH}_{4}+\mathrm{H}_{2} \mathrm{O}$ mixture hydrates form in the lowtemperature region. For example, the pressure drop effect of $\mathrm{TBAB}+\mathrm{DMSO}$ is better than that of THF + DMSO on the $\mathrm{CO}_{2}+\mathrm{CH}_{4}+\mathrm{H}_{2} \mathrm{O}$ hydrate formation at a certain temperature when the temperature below $285.55 \mathrm{~K}$, while the pressure drop effect of THF + DMSO is better than that of TBAB + DMSO on the $\mathrm{CO}_{2}+\mathrm{CH}_{4}+\mathrm{H}_{2} \mathrm{O}$ hydrate formation at a certain temperature when the temperature above $285.55 \mathrm{~K}$. On the other hand, although the pressure drop effect of both TBAB and THF on the $\mathrm{CO}_{2}+\mathrm{CH}_{4}+\mathrm{H}_{2} \mathrm{O}$ mixture hydrate formation will be slightly lower when them mixing with DMSO, the pressure drop effects of both $\mathrm{TBAB}+\mathrm{DMSO}$ and $\mathrm{THF}+$ DMSO are still remarkably better than that of neothexane. ${ }^{31}$ It demonstrates that, among the investigated additives, TBAB and

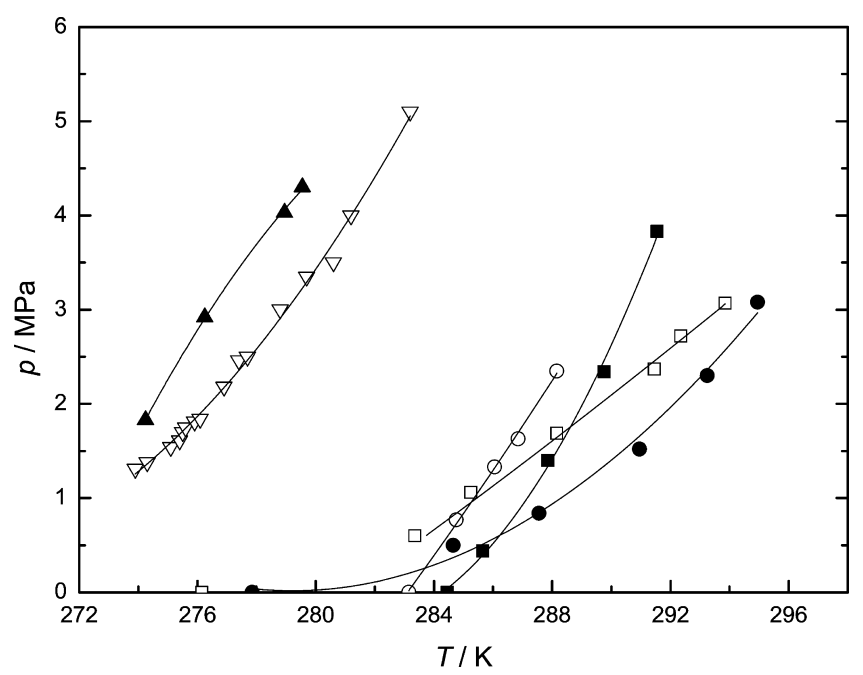

Figure 7. Comparison of the effects of different TBAB (3) + THF (4) $+\mathrm{DMSO}(5)+\mathrm{H}_{2} \mathrm{O}(6)$ aqueous solutions on equilibrium hydrate formation pressure of $\mathrm{CH}_{4}(0.55)+\mathrm{CO}_{2}(0.45)$ mixture. $\mathbf{\square}, x_{3}=$ $0.0234, x_{4}=x_{5}=0.0 ; \boldsymbol{\bullet}, x_{4}=0.0556, x_{3}=x_{5}=0.0 ; \mathbf{\Delta}, x_{5}=0.0156, x_{3}$ $=x_{4}=0.0 ; \square, x_{3}=0.0, x_{4}=0.0556, x_{5}=0.0156 ; O, x_{3}=0.0234, x_{4}=$ $0.0, x_{5}=0.0156 ; \nabla, \mathrm{CO}_{2}(0.5)+\mathrm{CH}_{4}(0.5)$ mixture gas with 0.1036 mol fraction of neohexane, Servio et al.; ${ }^{31}$ all of the lines are drawn as fitting curves of the experimental data.

THF have the best pressure drop effect on the $\mathrm{CO}_{2}+\mathrm{CH}_{4}+$ $\mathrm{H}_{2} \mathrm{O}$ hydrate formation, with $\mathrm{TBAB}+\mathrm{DMSO}$ and $\mathrm{THF}+$ DMSO following, then neohexane, and finally DMSO.

For the above measurements of the equilibrium hydrate formation conditions, the gas phase compositions at the equilibrium points were also measured and listed in Table 2, which can be regarded as a token of the relative solubility of $\mathrm{CO}_{2}+\mathrm{CH}_{4}$ in the different additive aqueous solutions. It can be seen from Table 2 that the mole fraction of $\mathrm{CO}_{2}$ in the gas phase at the equilibrium points of the mixture hydrate systems without any additives and with DMSO, TBAB, THF, TBAB + DMSO, and THF + DMSO is approximately 0.42, 0.33, 0.38, $0.38,0.37$, and 0.37 , respectively. It demonstrates that both DMSO and its mixture with TBAB or THF can considerably promote the solubility of $\mathrm{CO}_{2}$ in the solution, but the effect of DMSO is remarkable. This proves the prominent promotion effect of DMSO as a $\mathrm{CO}_{2}$ gas solvent in the water solution. Thus, DMSO may be a potential kinetic promoter for the $\mathrm{CO}_{2}$ mixture hydrate formation, although this should be proved by the kinetic study in the following work.

\section{CONCLUSION}

The equilibrium hydrate formation conditions for simulated landfill gas (LFG) $\left[\mathrm{CO}_{2}(0.45)+\mathrm{CH}_{4}(0.55)\right]$ with pure water and with TBAB, THF, DMSO, TBAB + DMSO, and THF + DMSO aqueous solutions have been experimentally investigated in this work. The gas phase compositions at the equilibrium points were also measured. The results illustrates that both TBAB and THF can remarkably reduce the equilibrium hydrate formation pressure of LFG mixture gas, while DMSO has no obvious pressure drop effect on the equilibrium hydrate formation conditions but has a considerable promoting effect on the solubility of $\mathrm{CO}_{2}$ in the solution. However, the mixture additives of TBAB + DMSO and THF + DMSO can not only remarkably promote the solubility of $\mathrm{CO}_{2}$ but also reduce the equilibrium hydrate formation pressure of 
$\mathrm{CO}_{2}+\mathrm{CH}_{4}+\mathrm{H}_{2} \mathrm{O}$ hydrate. Thus, DMSO may be a potential kinetic promoter for the $\mathrm{CO}_{2}$ mixture hydrate formation. Moreover, for the investigated additives, the pressure drop effect of THF or THF + DMSO is better than that of TBAB or $\mathrm{TBAB}+\mathrm{DMSO}$ on the $\mathrm{CO}_{2}+\mathrm{CH}_{4}+\mathrm{H}_{2} \mathrm{O}$ equilibrium hydrate formation in the high temperature region.

\section{AUTHOR INFORMATION}

\section{Corresponding Author}

*Tel. and fax: +86-20-87057037. E-mail: lixs@ms.giec.ac.cn.

\section{Funding}

This work was supported by the National Natural Science Foundation of China Grant No. 51076155, the National Key Basic Research \& Development Program (973) Grant No. 2009CB219507, the Science \& Technology Program of Guangdong Province Grant No. 2011A08043021), and the Key Research Program of the Chinese Academy of Sciences (KGZD-EW-XXX-Z), which are gratefully acknowledged.

\section{Notes}

The authors declare no competing financial interest.

\section{REFERENCES}

(1) Amini, H. R.; Reinhart, D. R. Regional prediction of long-term landfill gas to energy potential. Waste Manage. 2011, 31, 2020-2026.

(2) Park, J. W.; Shin, H. C. Surface emission of landfill gas from solid waste landfill. Atmos. Environ. 2001, 35, 3445-3451.

(3) Adrian, K. M.; Mostafa, A. W.; Rodrigo, D. Modeling greenhouse gas emissions for municipal solid waste management strategies in Ottawa,Ontario,Canada. Resour. Conserv. Recycl. 2008, 52, 1241-1251.

(4) Wang, W.; Luo, Y. X.; Deng, Z. Bioenergy recovery from landfill gas: A case study in China. Front. Environ. Sci. Eng. China 2009, 3, 2031.

(5) Kapdi, S. S.; Vijay, V. K.; Rajesh, S. K.; Prasad, R. Biogas scrubbing, compression and storage: perspective and prospectus in Indian context. Renewable Energy 2005, 30, 1195-1202.

(6) Lombardia, L.; Corti, A.; Carnevale, E.; Baciocchi, R.; Zingaretti, D. Carbon dioxide removal and capture for landfill gas up-grading. Energy Procedia 2011, 4, 465-472.

(7) Gaur, A.; Park, J. W.; Maken, S.; Song, H. J.; Park, J. J. Landfill gas (LFG) processing via adsorption and alkanolamine absorption. Fuel Process. Technol. 2010, 91, 635-640.

(8) Chang, H. M.; Chung, M. J.; Park, S. B. Integrated Cryogenic System for $\mathrm{CO}_{2}$ Separation and LNG Production from Landfill Gas. Adv. Cryog. Eng. 2010, 1218, 278-285.

(9) Sorensen, C. V.; Bailey, J. R. Landfill gas purification method and system. US 2011/0023710 A1, 2011.

(10) Duc, N. H.; Chauvy, F.; Herri, J. M. $\mathrm{CO}_{2}$ capture by hydrate crystallization - A potential solution for gas emission of steelmaking industry. Energy Convers. Manage. 2007, 48, 1313-1322.

(11) Linga, P.; Kumar, R.; Englezos, P. The clathrate hydrate process for post and pre-combustion capture of carbon dioxide. J. Hazard. Mater. 2007, 149, 625-629.

(12) Fan, S. S.; Li, S. F.; Wang, J. Q.; Lang, X. M.; Wang, Y. H. Efficient Capture of $\mathrm{CO}_{2}$ from Simulated Flue Gas by Formation of TBAB or TBAF Semiclathrate Hydrates. Energy Fuels 2009, 23, 42024208.

(13) Kang, S. P.; Seo, Y.; Jang, W.; Seo, Y. Gas Hydrate Process for Recovery of $\mathrm{CO}_{2}$ from Fuel Gas. Icheap-9: 9th Int. Conf. Chem. Process Eng., Pts 1-3 2009, 17, 1449-1454.

(14) Kumar, R.; Linga, P.; Ripmeester, J. A.; Englezos, P. Two-Stage Clathrate Hydrate/Membrane Process for Precombustion Capture of Carbon Dioxide and Hydrogen. J. Environ. Eng. 2009, 135, 411-417.

(15) Li, X. S.; Xia, Z. M.; Chen, Z. Y.; Yan, K. F.; Li, G.; Wu, H. J. Equilibrium Hydrate Formation Conditions for the Mixtures of $\mathrm{CO}_{2}+$ $\mathrm{H}_{2}+$ Tetrabutyl Ammonium Bromide. J. Chem. Eng. Data 2010, 55, $2180-2184$.
(16) Li, X. S.; Xia, Z. M.; Chen, Z. Y.; Yan, K. F.; Li, G.; Wu, H. J. Gas Hydrate Formation Process for Capture of Carbon Dioxide from Fuel Gas Mixture. Ind. Eng. Chem. Res. 2010, 49, 11614-11619.

(17) Acosta, H. Y.; Bishnoi, P. R.; Clarke, M. A. Experimental Measurements of the Thermodynamic Equilibrium Conditions of Tetra-n-butylammonium Bromide Semiclathrates Formed from Synthetic Landfill Gases. J. Chem. Eng. Data 2011, 56, 69-73.

(18) Li, X. S.; Xia, Z. M.; Chen, Z. Y.; Wu, H. J. Precombustion Capture of Carbon Dioxide and Hydrogen with a One-Stage Hydrate/ Membrane Process in the Presence of Tetra-n-butylammoniurn Bromide (TBAB). Energy Fuels 2011, 25, 1302-1309.

(19) Kim, S. M.; Lee, J. D.; Lee, H. J.; Lee, E. K.; Kim, Y. Gas hydrate formation method to capture the carbon dioxide for pre-combustion process in IGCC plant. Int. J. Hydrogen Energy 2011, 36, 1115-1121.

(20) Li, X. S.; Xu, C. G.; Chen, Z. Y.; Wu, H. J. Tetra-n-butyl ammonium bromide semi-clathrate hydrate process for postcombustion capture of carbon dioxide in the presence of dodecyl trimethyl ammonium chloride. Energy 2010, 35, 3902-3908.

(21) Li, X. S.; Xu, C. G.; Chen, Z. Y.; Wu, H. J. Hydrate-based precombustion carbon dioxide capture process in the system with tetra-nbutyl ammonium bromide solution in the presence of cyclopentane. Energy 2011, 36, 1394-1403.

(22) Sloan, E. D. Clathrate Hydrates of Natural Gases, 2nd ed.; Marcel Dekker: New York, 1998.

(23) Tajima, H.; Yamasaki, A.; Kiyono, F. Energy consumption estimation for greenhouse gas separation processes by clathrate hydrate formation. Energy 2004, 29, 1713-1729.

(24) Kang, S. P.; Lee, H. Recovery of $\mathrm{CO}_{2}$ from flue gas using gas hydrate: Thermodynamic verification through phase equilibrium measurements. Environ. Sci. Technol. 2000, 34, 4397-4400.

(25) Martin, D.; Hauthal, H. G. Dimethyl Sulphoxide; Wiley: New York, 1975.

(26) Luzar, A.; Chandler, D. Structure and Hydrogen-Bond Dynamics of Water-Dimethyl Sulfoxide Mixtures by ComputerSimulations. J. Chem. Phys. 1993, 98, 8160-8173.

(27) Department of the Army. Landfill off-gas collection and treatment systems. EM 1110-1-4016. U.S. Army Corps of Engineers, Washington, DC, 2008. http://140.194.76.129/publications/engmanuals/em1110-1-4016/entire.pdf.

(28) Ohgaki, K.; Makihara, Y.; Takano, K. Formation of $\mathrm{CO}_{2}$ Hydrate in Pure and Sea Waters. J. Chem. Eng. Jpn. 1993, 26, 558-564.

(29) Hashimoto, S.; Murayama, S.; Sugahara, T.; Ohgaki, K. Phase equilibria for $\mathrm{H}_{2}+\mathrm{CO}_{2}+$ tetrahydrofuran + water mixtures containing gas hydrates. J. Chem. Eng. Data 2006, 51, 1884-1886.

(30) Gaudette, J. Phase Equilibria and Solubility Measurements of Gases in Water in The Hydrate Formation Region; Masters Thesis, Engineering, McGill University, Montreal, Quebec, Canada, 2007.

(31) Servio, P.; Lagers, F.; Peters, C.; Englezos, P. Gas hydrate phase equilibrium in the system methane-carbon dioxide-neohexane and water. Fluid Phase Equilib. 1999, 158, 795-800.

(32) Deaton, W. M.; Frost, E. M. Gas Hydrates and Their Relation to the Operation of Natural Gas Pipelines; U.S. Bureau of Mines: Washington, DC, 1946.

(33) Oyama, H.; Shimada, W.; Ebinuma, T.; Kamata, Y.; Takeya, S.; Uchida, T.; Nagao, J.; Narita, H. Phase diagram, latent heat, and specific heat of TBAB semiclathrate hydrate crystals. Fluid Phase Equilib. 2005, 234, 131-135.

(34) Delahaye, A.; Fournaison, L.; Marinhas, S.; Chatti, I.; Petitet, J. P.; Dalmazzone, D.; Furst, W. Effect of THF on equilibrium pressure and dissociation enthalpy of $\mathrm{CO}_{2}$ hydrates applied to secondary refrigeration. Ind. Eng. Chem. Res. 2006, 45, 391-397.

(35) Matvienko, V. G.; Yarym-Agaev, N. L. Liquid-vapor equilibrium and volume properties of the liquid phase in the gammabutyrolactone-carbon dioxide system at elevated pressures. Russ. J. Appl. Chem. 1999, 72, 1139-1143.

(36) Lu, W. J.; Chou, I. M.; Burruss, R. C.; Song, Y. C. A unified equation for calculating methane vapor pressures in the $\mathrm{CH}_{4}-\mathrm{H}_{2} \mathrm{O}$ system with measured Raman shifts. Geochim. Cosmochim. Acta 2007, 71, 3969-3978. 